\title{
Multi-year trend analysis of childhood immunization uptake and coverage in Nigeria
}

\author{
Oyelola A. Adegboye, Danelle Kotze and Olasunkanmi A. Adegboye
}

\section{Summary:}

As a leading indicator of child health, under-five mortality was incorporated in the United Nations Millennium Development Goals with the aim of reducing the rate by two-thirds between 1990 and 2015. Under-five mortality in Nigeria is alarmingly high, and many of the diseases that result in mortality are vaccine preventable. This study evaluates the uptake of childhood immunization in Nigeria from 1990 to 2008. A multi-year trend analysis was carried out using Alternating Logistic Regression on 46,130 children nested within 17,380 mothers in 1938 communities from the Nigerian Demographic and Health Surveys from 1990 to 2008. The findings reveal that mother-level and community-level variability are significantly associated with immunization uptake in Nigeria. The model also indicates that children delivered at private hospitals have a higher chance of being immunized than children who are delivered at home. Children from the poorest families (who are more likely to be delivered at home) have a lower chance of being immunized than those from the richest families (OR 1/4 0.712; 95\% CI, 0.641-0.792). Similarly, the chance of children with a mother with no education being immunized is decreased by $17 \%$ compared with children whose mother has at least a primary education. In the same way, children of mothers who are gainfully employed and those of older mothers have statistically significantly higher odds of being immunized. Children of households with a female head are less likely to be immunized than those from male-headed households. The statistical significance of the community-survey year interaction term suggests an increase in the odds of a child being immunized over the years and spread over communities. Evidence-based policy should lay more emphasis on mother- and community- level risk factors in order to increase immunization coverage among Nigerian children.

\section{Introduction}

Under-five mortality in Africa is at an alarming level, with about $40 \%$ of global deaths occurring in sub-Sahara Africa. As a leading indicator of level of child health, the under-five mortality rate has been incorporated by most United Nations (UN) member states as a UN Millennium Development Goal (MDG) indicator (Goal 4), with the goal of reducing the under-five mortality rate by two-thirds by 2015 (United Nations, n.d.). Although the developmental agenda emboldened in the MDGs addresses all countries of the world, there can be no doubt that subSaharan African countries stand to benefit most from the promotion of its principles 
as compared with other regions of the world. In comparison with the rest of the world, sub-Saharan African countries have the highest rates of poverty and illiteracy as well as the highest rates of child and maternal mortality, and hence the importance of MDG-4 to this region.

Despite the decrease in the under-five mortality rate in Nigeria from 213 per 1000 live births in 1990 to 143 per 1000 live births in 2010, Nigerian under-five mortality was ranked 12th worldwide in 2010 (Adegboye, 2010; UNICEF, 2010). The total fertility rate was 4.82 (average number of children per woman in 2010) and life expectancy at birth was 51 years (UNICEF, 2010). Several factors have been identified to have significant impact on under-five mortality: pneumonia, diarrhoea, poverty, lack of safe water and poor sanitation, mother's education and mother's age (Adegboye, 2010). Others have found poor socioeconomic development, a weak health care system and high socio-cultural barriers to care utilization as associated risk factors for the high rate of maternal and child mortality in Nigeria (Ogunjimi et al., 2012); people's beliefs, attitudes and behavioural practices (Ogunjuyigbe, 2004) add to the burden. Bosch-Capblanch et al. (2012) found caregiver's and partner's education, and caregiver's tetanus toxoid status to be strongly associated with being unvaccinated. Also, Kayode et al. (2012) reported that the mother's age at first marriage plays an important role in reducing underfive mortality in Nigeria; other favourable practices include health-seeking behaviour, breast-feeding children for more than 18 months, use of contraception, small family size, having one wife, low birth order, normal birth weight, child spacing, living in urban areas and good sanitation.

Immunization remains the most important and cost-effective public health intervention, protecting individuals, families and communities from vaccinepreventable diseases and conferring herd immunity thereby breaking cycles of disease transmission. It also serves as a response to outbreaks of diseases as well as an in-road for other primary health care services. However, routine immunization coverage in Nigeria has continued to fall below average. Preventable infectious diseases such as tuberculosis, poliomyelitis, diphtheria, tetanus and measles are the main causes of morbidity and mortality in children, especially in developing countries like Nigeria. Vaccination is a very effective way of reducing (and where possible eradicating) the spread of these preventable diseases. The Nigeria Expanded Program on Immunization (EPI) was introduced in 1979, was restructured and renamed the National Programme on Immunization (NPI) in 1997 and later merged with the National Primary Health Care Development Agency (NPHCDA) in 2007. The main goal of the immunization programme is to develop, promote and sustain the immunization programme towards reducing childhood morbidity and mortality through adequate immunization coverage (90\% by the year 2020) of at-risk populations. 
Table 1. Schedule of antigens for children under the age of 12 months, Nigeria, 1990-2008

\begin{tabular}{llll}
\hline Contact No. & Antigens & Schedule & Dosage \\
\hline First & Bacillus Calmette-Guérin (BCG) & At birth & $0.05 \mathrm{ml}$ \\
Second & Diphtheria, Pertussis and Tetanus (DPT) I & 6 weeks & $0.5 \mathrm{ml}$ \\
Second & Oral polio vaccine (OPV) I & 6 weeks & $2 \mathrm{drops}$ \\
Third & Diphtheria, Pertussis and Tetanus (DPT) II & 10 weeks & $0.5 \mathrm{ml}$ \\
Third & Oral polio vaccine (OPV) II & 10 weeks & $2 \mathrm{drops}$ \\
Fourth & Diphtheria, Pertussis and Tetanus (DPT) III & 14 weeks & $0.5 \mathrm{ml}$ \\
Fourth & Oral polio vaccine (OPV) III & 14 weeks & $2 \mathrm{drops}$ \\
Fifth & Measles & 9 months & $0.5 \mathrm{ml}$ \\
\hline
\end{tabular}

It was designed to reach children from birth to five years of age, all pregnant women and at-risk populations. It is expected that a fully vaccinated child should have received a Bacillus Calmette-Gué rin (BCG), three doses of Diphtheria Pertussis and Tetanus (DPT), at least three doses of poliomyelitis and one dose of measles vaccines by their first birthday (National Population Commission (NPC) [Nigeria] \& ICF Macro, 2009) (see Table 1 for details of vaccines). In 2004, the country included hepatitis B and yellow fever vaccines in its immunization schedule. By 2012 the Haemophilus influenzae type b 'Hib' vaccine was added to form a pentavalent vaccine consisting of diphtheria, pertussis, tetanus, hepatitis B and Haemophilus influenzae type $b$.

The use of poliomyelitis vaccines has eliminated the disease in many countries. After the World Health Assembly in 1988 resolved to eradicate poliomyelitis globally, the number of poliomyelitis-endemic countries reduced from more than 125 countries in 1988 to four countries (Afghanistan, India, Nigeria and Pakistan) in August 2008 (WHO, 2008). The new statistics from WHO showed that only Afghanistan, Nigeria and Pakistan remain poliomyelitis endemic (with Nigeria at the top of the list), while Chad and Niger are classified as non-endemic countries (WHO, 2012a). Although there has been a $71 \%$ global decrease in deaths due to measles from 542,000 in 2000 to 158 ,000 in 2011, while new cases dropped by $58 \%$ during the same period, this success story due to vaccination is dented by the high number of children that did not receive the first-dose measles vaccine in 2011 (20 million worldwide with 1.7 million alone in Nigeria) (WHO, 2012b). Nigeria recorded the third highest number of new cases of measles in 2011 (18,843 cases), preceded by India (29,339 cases) and DRC with 134,042 new cases.

Success towards achieving the target of having $80 \%$ or above of children fully immunized is still a problem. Coverage in many parts of Nigeria has fallen below 50\% (Antai, 2009; Kunle-Olowu et al., 2011; Abdulraheem et al., 2011). The decline in the attainment of the universal child immunization target in Nigeria in 1990 can be attributed to a number of factors: from political will to poor service delivery, culture, funding, community involvement and beliefs (Federal Ministry of Health, Nigeria). Problems of immunization uptake in Nigeria have been associated with mothers' poor knowledge of immunization against targeted diseases, parents' concern about immunization safety, long waiting time at the health facility and long 
distance from the hospital (Maekawa et al., 2007; Abdulraheem et al., 2011). Apart from these problems, false believe in contraindications to immunization like catarrh and mild fever in the child at the time of immunization, failure to administer simultaneously all vaccines for which the child was eligible and lack of information on the vaccination regimen are reported causes of missed opportunities to immunize in Nigeria (Kabir et al., 2004; Adeiga et al., 2005; Onyiriuka et al., 2005; Anah et al., 2006).

The safety of pregnant women and their babies depends on the success of the programme. Wammanda et al. (2011) reported that only $22 \%$ of children receive their BCG within the first 3 days of life and $36.2 \%$ within the first 7 days of life. Adeiga et al. (2005) indicated that reasons for failure to immunize or complete the immunization of children included poor knowledge of immunization and belief about immunization in $47 \%$, lack of information in $40.7 \%$ and lack of motivation in $11.6 \%$, and only $11 \%$ of the children in their study were not vaccinated against measles in the Lagos metropolis.

The Demographic and Health Survey (DHS) is a national representative survey that provides information on the population and health situation of a country. The main interest of the survey is specifically to collect information on fertility, family planning, maternal and child health, immunization, educational characteristics, wealth index, ownership of basic facilities and HIV/AIDS at household and individual levels. For this study, similar variables were extracted from all four surveys conducted in 1990, 1999, 2003 and 2008 at the community and mother level. Clusters were introduced at two levels: first, children sharing the same mother-level characteristics such as age of parents, parents' education, number of rooms, wealth index, household head and so on; and second, children from the same community sharing the same community-level characteristics, such as availability of and distance to health care facilities and place of residence. This study's outcome variable is whether a child has been fully immunized or not, which is at the child's level but nested within mother and within a community, thus introducing dependency in the data.

For clustered binary outcomes, several approaches have been suggested: Generalized Estimating Equations (GEE) techniques developed by Liang \& Zeger (1986) to extend the Generalized Linear Models (GLM) to accommodate correlated data. Dependencies between observations are handled by fitting the vector of parameters, using the GEE techniques, wherein the covariance matrix is structured by using a working correlation matrix fully specified by the vector of parameters. It is often preferred to talk in terms of association rather than correlation when dealing with a binary response and it is important to make inferences about the association between any two measurements within a cluster. Carey et al. (1993) proposed Alternating Logistic Regression (ALR) as an alternative to GEE. Alternating Logistic Regression simultaneously regresses the response on explanatory variables as well as modelling the association among responses in terms of pair-wise odds ratios. This method uses the odds ratio to capture association between categorical outcomes. The odds ratio is a particularly straightforward measure to capture association between 
categorical outcomes (Molenberghs \& Lesaffre, 1994; Fitzmaurice et al., 2004). These models estimate Pair-Wise Odds Ratios (POR) to capture the association structure between clustered binary data (Diggle et al., 1994). Molenberghs \& Verbeke (2006, p. 217) praised ALR as a tool to fit a marginal model based on odds ratios in a way that inferences can be made, not only about the marginal parameters, but about the pair-wise association as well.

The goal of this study was to identify the associated risk factors and estimate the mother- and community-level clustering of the immunization status of children between 12 months and 59 months of age, in order to evaluate the impact of immunization programmes and assess their coverage in Nigeria.

\section{Data source \\ Methods}

The data for this study were obtained from the Nigerian Demographic and Health Surveys (NDHS) implemented by the National Population Commission with technical support from ICF Macro. The NDHS started in 1990 and follow-up surveys were done in 1999, 2003 and 2008. The information collected included key health indicators for women aged 15-49 years, men aged 15-59 years and children between the ages of $\mathrm{O}$ and 5 years (National Population Commission (NPC) [Nigeria] \& ICF Macro, 2009). These are national representative data that are available for download with permission from the website of Measure DHS (http://www.measuredhs.com/).

The data sets consist of 46,130 children aged 12-59 months from 17,380 mothers in 1938 communities. The motivation for assessing the immunization status of children between the ages of 12 and 59 months is that: (i) generally all children should have completed the Nigerian immunization schedule by 12 months of age; (ii) most cases of vaccine-preventable death occur before the age of 5 years (under-five mortality rate is a well known child health index). Moreover, those children who are not immunized within 'the standard timeframe' may not necessarily get immunized at an older age because the parents may presume that they are out of the immunization age range based on the television and radio enlightenment jingles that emphasize the timeframe for immunization.

The outcome variable is whether a child has fully completed his/her immunization schedule by receiving all eight doses of antigens or not (Table 1). The other explanatory variables include the child-, mother- and community-specific variables. There are two levels of clustering used in the study: mother and community. Communities were identified using the Primary Sampling Unit (PSU) referred to as a cluster in the NDHS. Tables 2 and 3 summarize the demographic characteristics and list the variables.

\section{Statistical analysis}

Multi-level analysis was applied to identify associated factors for partial or nonimmunization of a child. Let yijk be the kth binary response ( yijk =1, completed, or $y i j k=0$, not completed his/her immunization) from a child of the $\mathrm{jth}$ mother

\section{http://repository.uwc.ac.za}


(sub-cluster) in the ith community (cluster). The interest here is in fitting a marginal probability of a child not completing his/her immunization schedule, pijk $=\operatorname{Pr}($ yijk = 1), given as:

$$
\operatorname{logit}\left(\pi_{i j k}\right)=x_{i j k}^{\prime} \beta
$$

Table 2. Variables and their definitions

\begin{tabular}{|c|c|}
\hline Variable & Categories \\
\hline Survey year & $1990,1999,2003,2010$ \\
\hline Region & $\begin{array}{l}\text { North-East, North-Central, North-West, South-East, South-West, } \\
\text { South-South }\end{array}$ \\
\hline \multicolumn{2}{|r|}{ ( } \\
\hline $\begin{array}{l}\text { Completed all } \\
\text { immunization }\end{array}$ & Yes or no \\
\hline Sex of child & Male or female \\
\hline Place delivery & Hospital (public and private) or home \\
\hline \multicolumn{2}{|l|}{ Mother level } \\
\hline Wealth quintile & Poorest, poorer, middle, richer, richest \\
\hline Religion & Catholic, Protestant, Other Christian, Islam, Traditionalist, Other \\
\hline Mother's age & Age of mother in years \\
\hline Mother's education & No education vs at least primary education \\
\hline Mother's occupation & $\begin{array}{l}\text { Currently employed or worked in the } 12 \text { months preceding the } \\
\text { survey vs Not }\end{array}$ \\
\hline Age at first birth & Mother's age at first birth \\
\hline Mother's marital status & $\begin{array}{l}\text { Never married, married, living together, widowed, divorced or not } \\
\text { living together }\end{array}$ \\
\hline Sex of household head & Male or female \\
\hline \multicolumn{2}{|l|}{ Community level } \\
\hline Wealth & $\begin{array}{l}\text { Proportion in the lowest and second lowest wealth quintile in the } \\
\text { community }\end{array}$ \\
\hline Place of residence & Rural or urban \\
\hline Time to source of water & Mean time to source of water \\
\hline Sanitation & Proportion in the community with bad sanitation \\
\hline Access to clean water & Proportion in the community with access to clean and safe water \\
\hline
\end{tabular}

where $\mathrm{xijk}$ is the vector of covariates at each cluster level. The association model for the pair-wise odds ratios (POR) among observations with three-level cluster data is given as:

$$
\log \operatorname{POR}\left(Y_{i j k}, Y_{i j^{\prime} k^{i}}\right)=\alpha_{0}+\alpha_{1} z_{i j k j^{\prime} k^{\prime}}^{\prime}
$$

where $z i j k j^{\prime} k^{\prime}=1$ if the pair of observations is from the same subcluster $\left(j=j^{0}\right)$ and $o$ otherwise, a $a_{0}$ is the log odds ratio for association among observations from different subclusters, and $\mathrm{a}_{0} \mathrm{~b} \mathrm{a}_{1}$ is the $\log$ odds ratio for within-subcluster association (Preisser et al., 2003). 
Four kinds of models were specified: Model 1, which is the null model, was fitted to examine whether the mother- or community-level ORs varied. The second model (Model 2) contains the survey year, community and the interaction term survey year and community, while the third model (Model 3) contains the survey year and other explanatory variables, and Model 4 includes all explanatory variables plus the interaction terms. All models were implemented in SAS procedures PROC GENMOD (SAS Institute Inc., 2008).

Table 3. Summary of vaccination uptake in Nigeria from 1990 to 2008

\begin{tabular}{lccccc}
\hline & \multicolumn{5}{c}{ Survey year } \\
\cline { 2 - 6 } Characteristic & 1990 & 1999 & 2003 & 2008 & Total \\
\hline Number of communities (clusters) & 298 & 393 & 361 & 886 & 1938 \\
Number of households & 3995 & 2837 & 2161 & 11,014 & 17,380 \\
Number of observations & 7902 & 3553 & 6029 & 28,647 & 46,130 \\
Percentage fully vaccinated & $60.32 \%$ & $63.70 \%$ & $77.69 \%$ & $70.68 \%$ & $68.97 \%$ \\
\hline
\end{tabular}

\section{Results}

About $60 \%, 64 \%, 78 \%$ and $71 \%$ of the children in the study were fully vaccinated in 1990, 1999, 2003 and 2008, respectively (Table 3). In the NDHS 2008, 62\% had their birth delivered at home: $13 \%$ at private health facilities and $20 \%$ at a public health facility (National Population Commission (NPC) [Nigeria] \& ICF Macro, 2009). Figure 1 illustrates the distribution of vaccination by place of delivery. The proportions of children that were not fully immunized among those delivered at home were $37.5 \%$ in $1990,36.7 \%$ in $1999,31.6 \%$ in 2003 and $32.2 \%$ in 2008 . As shown in Fig. 2, the percentage and distribution of antigens taken varies; for example, in 2008 about $47 \%$ received BCG only, $67 \%$ received the first dose of polio vaccine only, $58 \%$ took the second dose of polio vaccine and $40 \%$ took the third dose of polio vaccine. Also, about 49\% received only the first dose of DPT, 33\% received DPT2, 20\% received DPT3 and 43\% received the measles vaccine only.

Table 4 presents the odds ratio estimates together with the 95\% confidence interval from the ALR model (of different specifications) for the associated risk factors for a child not completing the set of antigens. Accounting for the clustering (mother and community) in the vaccination uptake was handled by pair-wise odds ratios (PORs). The PORs indicate the association between pairs of observations from children with the same mother-level characteristics or in the same community. Evidence from Model 1, without adjusting for any covariates, indicated a significant mother-level variability $(\mathrm{OR}=87.96, \mathrm{p}<0.0001)$ and community-level variability $(\mathrm{OR}=33.22, \mathrm{p}<0.0001)$. The result also showed that the mother-level clustering ( $\mathrm{POR}=92.08,157.71$ and 156.04) and the community-level clustering ( $\mathrm{POR}=36.97,79.25$ and 78.81), after adjusting risk factors in Model 2, Model 3 and Model 4, respectively, were statistically significant. A simpler model (Model 1) with only the survey year (not shown) shows a significant association between the survey year and the odds of being immunized: the estimated odds ratio of a child being immunized in 1999 was OR $=1.189$ (95\% CI, $0.922-1.528$ ), in 2003 it was OR $=4.506$ (95\% CI, 3.171-6.403) and in 2008 it was 
$\mathrm{OR}=1.836$ (95\% CI, 1.439-2.342) compared with 1990.

The results from Model 2, with two-way interaction between survey year and community, showed a significant interaction term indicating an increase in the odds of a child being immunized over time and space by $0.2 \%$ and $0.3 \%$ in 1999 and 2008, respectively, compared with 2003. The three models (Model 2, Model 3 and Model 4) showed a significant increase in the chance of being immunized in 1999, 2003 and 2008 compared with 1990.

1990

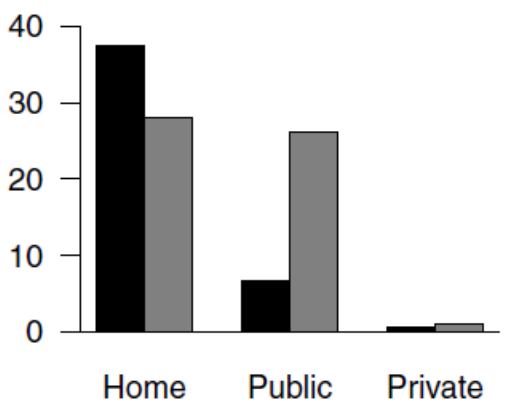

2003

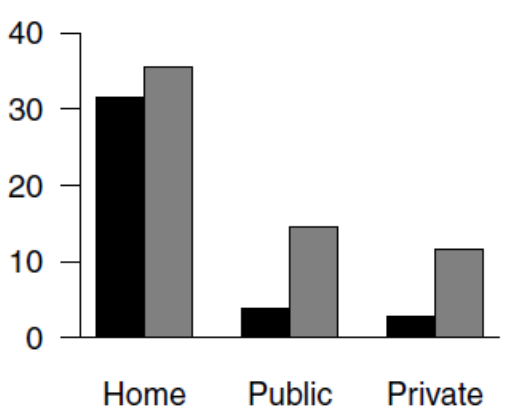

1999

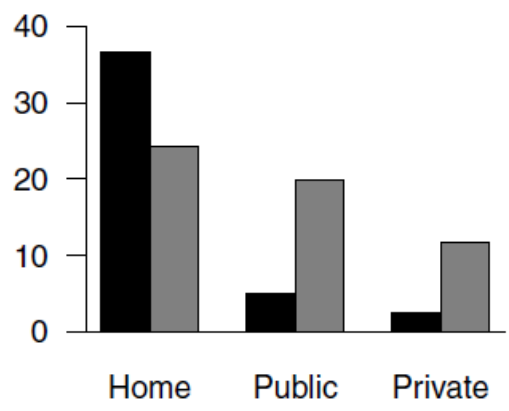

2008

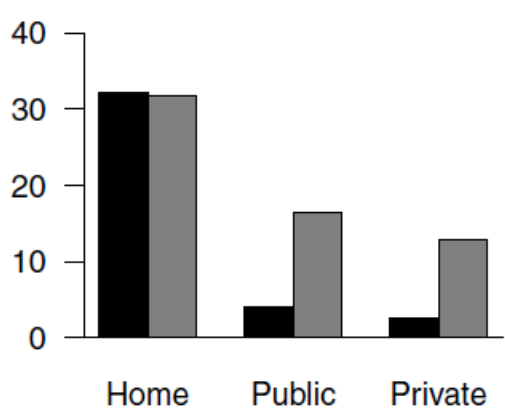

Fig. 1. Proportion of children in Nigeria having received the full schedule of immunization (grey) or not (dark) by year and place of delivery.

The inclusion of additional risk factors also increased the within-community clustering POR from 36.97 in Model 2, to 79.25 in Model 3 and to 78.81 in Model 4. A similar pattern was observed with the within-mother clustering.

The results from the final model (Model 4), in which all the risk factors that were considered in this study were adjusted for, together with the interaction term (survey year and community), are displayed in Table 4. The final model also indicates that children delivered at hospitals have about a $42 \%$ higher chance (OR 1/4 1.415; 95\% CI, 1.304-1.535) of being immunized than children delivered at home.

The estimated odds ratio shows that children from the poorest families have a greater chance than those from the richest families of being immunized (OR 1/4 0.712; 95\% CI, 0.641-0.792). Mother's education is a significant risk factor for childhood immunization, with children of mothers with no education having a 
lower chance of being immunized than those of mothers with at least a primary education (OR 0.844). In the same regard, the proportion of fully immunized children was higher when the mother is gainfully employed (mother's occupation) than when she is not gainfully employed (OR 1/4 1.001; 95\% CI, 1.000-1.001).

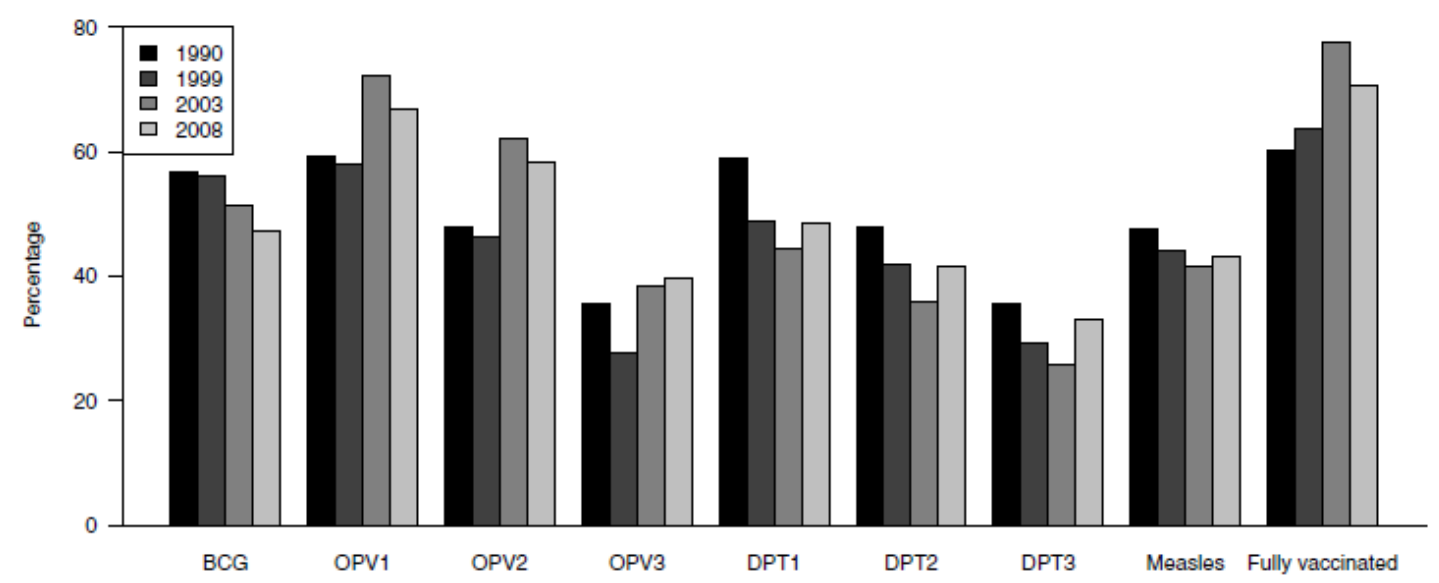

Fig. 2. Percentage of children having received different sets of antigens in Nigeria (1990-2008).

The likelihood of a child being fully immunized increased with age: greater age is statistically significantly associated with higher odds of a child being immunized (OR 1/4 1.012; 95\% CI, 1.006-1.017). Children from households with a female head are 0.926 times less likely to be immunized than those from a male-headed household (OR 1/4 0.926; 95\% CI, 0.861-0.996). An increase in the proportion of households with good sanitation in communities increases the chance of a child being immunized (OR $1 / 4$ 1.006; 95\% CI, 1.004-1.009).

\section{Discussion and Conclusion}

Vaccination is a very effective way of eradicating the burden of a large number of preventable diseases that account for approximately $22 \%$ of child deaths in Nigeria, amounting to over 200,00o deaths per year (USAID, n.d.). The results of this study show the advantage of the use of Alternating Logistic Regression, which allows estimation of the correlations using pair-wise odds ratios in the data set. The inclusion of within-cluster association improved the inference (Preisser et al., 2003) on the risk factors for vaccination uptake in Nigeria. Regardless of the adjusted risk factors, the mother-level and community-level variability remain statistically significant. This study confirms the mother- and community-level clustering, reaffirming that children with the same mother-level characteristics or in the same community exhibit a similar likelihood of been immunized (Diddy, 2009; Wiysonge et al., 2012).

The geographical heterogeneity in the coverage of vaccination can be attributed to variations between communities within the different regions in Nigeria. The South-South region in particular is characterized by extensive mangrove forests, lagoons and swamps stretching over hundreds of kilometres inland, as well as poverty, poor social infrastructure and conflicts that are exacerbated by 
environmental degradation from crude oil pollution (Diddy, 2009). Sorungbe (1989) suggested regular review of the programme and intensive training of personnel. The mother-level variability confirmed in this study attested to Abdulraheem et al. (2011), who claimed that long-distance trekking and the high cost of transportation are limiting factors for mothers completing immunization schedules for their children. Routine immunization in northern Nigeria is one the lowest in the world. The region is known to be hesitant about immunization uptake, and this has been attributed to cultural beliefs and interpretations, health worker malpractices, fear of injection, level of education and lack of adequate knowledge about immunization (Renne, 2010).

Table 4. Odds ratio estimates from ALR models for associated risk factors for unimmunized children in Nigeria, $1990-2008$

\begin{tabular}{|c|c|c|c|c|c|c|}
\hline \multirow[b]{2}{*}{ Risk factor } & \multicolumn{2}{|c|}{ Model 2} & \multicolumn{2}{|c|}{ Model 3} & \multicolumn{2}{|c|}{ Model 4} \\
\hline & OR & $95 \% \mathrm{CI}$ & OR & $95 \% \mathrm{CI}$ & OR & $95 \% \mathrm{CI}$ \\
\hline \multicolumn{7}{|l|}{ Survey year } \\
\hline 1999 vs 1990 & $2.060 *$ & $1.175,3.611$ & $1.776^{*}$ & $1.147,2.750$ & $1.788^{*}$ & $1.014,3.155$ \\
\hline 2003 vs 1990 & $2.071^{*}$ & $1.115,3.849$ & $3.529^{*}$ & $2.528,4.924$ & $3.191 *$ & $1.709,5.958$ \\
\hline 2008 vs 1990 & 0.660 & $0.390,1.119$ & $1.283^{*}$ & $1.013,1.626$ & 0.946 & $0.548,1.633$ \\
\hline Community & 1.000 & $0.999,1.001$ & $1.000 *$ & $1.000,1.000$ & 1.000 & $1.000,1.000$ \\
\hline Community $\times 1990$ & 0.999 & $0.999,1.000$ & & & 1.000 & $1.000,1.000$ \\
\hline Community $\times 1999$ & $1.002 *$ & $1.000,1.004$ & & & 1.000 & $0.998,1.003$ \\
\hline Community $\times 2008$ & $1.003^{*}$ & $1.002,1.003$ & & & $1.001 *$ & $1.000,1.001$ \\
\hline \multicolumn{7}{|l|}{ Region } \\
\hline Central vs South-West & & & 0.900 & $0.779,1.039$ & 0.938 & $0.809,1.087$ \\
\hline North-East vs South-West & & & $1.318^{*}$ & $1.110,1.565$ & $1.444 *$ & $1.192,1.749$ \\
\hline North-West vs South-West & & & $0.786^{*}$ & $0.677,0.913$ & 0.870 & $0.736,1.029$ \\
\hline South-East vs South-West & & & $0.713^{*}$ & $0.615,0.826$ & $0.691 *$ & $0.593,0.804$ \\
\hline South-West vs South-West & & & 1.190 & $0.975,1.452$ & 1.077 & $0.863,1.344$ \\
\hline Child's sex & & & 0.994 & $0.970,1.018$ & 0.993 & $0.969,1.018$ \\
\hline \multicolumn{7}{|l|}{ Place of delivery } \\
\hline Hospital vs home & & & $1.409^{*}$ & $1.299,1.529$ & $1.415^{*}$ & $1.304,1.535$ \\
\hline \multicolumn{7}{|l|}{ Residence } \\
\hline Rural vs urban & & & 0.873 & $0.732,1.042$ & 0.857 & $0.716,1.026$ \\
\hline \multicolumn{7}{|l|}{ Wealth Index } \\
\hline Poorest vs richest & & & $0.711^{*}$ & $0.639,0.791$ & $0.712 *$ & $0.641,0.792$ \\
\hline Poorer vs richest & & & $0.813^{*}$ & $0.747,0.886$ & $0.815^{*}$ & $0.749,0.888$ \\
\hline Middle vs richest & & & 0.934 & $0.858,1.017$ & 0.935 & $0.859,1.018$ \\
\hline Richer vs richest & & & $1.201^{*}$ & $1.087,1.327$ & $1.201 *$ & $1.087,1.326$ \\
\hline Age at fist marriage & & & 0.999 & $0.988,1.010$ & 0.998 & $0.987,1.009$ \\
\hline \multicolumn{7}{|l|}{ Mother's marital status } \\
\hline Never married vs divorced or separated & & & 1.056 & $0.914,1.219$ & 1.059 & $0.917,1.223$ \\
\hline Married vs divorced or separated & & & 0.939 & $0.734,1.201$ & 0.943 & $0.738,1.205$ \\
\hline Living together vs divorced or separated & & & 1.034 & $0.781,1.369$ & 1.033 & $0.780,1.369$ \\
\hline Widowed vs divorced or separated & & & 0.832 & $0.594,1.165$ & 0.831 & $0.593,1.165$ \\
\hline
\end{tabular}

Table 4. Continued

\begin{tabular}{|c|c|c|c|c|c|c|}
\hline \multirow[b]{2}{*}{ Risk factor } & \multicolumn{2}{|c|}{ Model 2} & \multicolumn{2}{|c|}{ Model 3} & \multicolumn{2}{|c|}{ Model 4} \\
\hline & OR & $95 \% \mathrm{CI}$ & OR & $95 \% \mathrm{CI}$ & OR & $95 \% \mathrm{CI}$ \\
\hline Mother's education (none vs at least primary) & & & $0.846^{*}$ & $0.762,0.940$ & $0.844^{*}$ & $0.760,0.937$ \\
\hline Mother's age & & & 1.012 & $1.006,1.017$ & $1.012 *$ & $1.006,1.017$ \\
\hline Mother's occupation (gainfully employed ) & & & $1.001 *$ & $1.000,1.001$ & $1.001 *$ & $1.000,1.001$ \\
\hline Household head (female) & & & $0.924 *$ & $0.860,0.993$ & $0.926^{*}$ & $0.861,0.996$ \\
\hline Prop. of $40 \%$ poorest & & & 0.997 & $0.994,1.000$ & 0.998 & $0.994,1.001$ \\
\hline \multicolumn{7}{|l|}{ Religion } \\
\hline Catholic vs Other Christian & & & 1.071 & $0.900,1.275$ & 1.058 & $0.887,1.261$ \\
\hline Catholic vs Islam & & & 0.788 & $0.658,0.943$ & 0.836 & $0.695,1.005$ \\
\hline Catholic vs Traditionalist & & & 0.575 & $0.451,0.733$ & $0.558 *$ & $0.440,0.707$ \\
\hline Catholic vs Other & & & 0.655 & $0.412,1.042$ & 0.663 & $0.415,1.060$ \\
\hline Average time to water source & & & 0.999 & $0.998,1.000$ & 0.999 & $0.998,1.001$ \\
\hline Prop. with clean water & & & 1.001 & $0.998,1.004$ & 1.001 & $0.998,1.004$ \\
\hline Prop. with good sanitation & & & $1.006^{*}$ & $1.004,1.009$ & $1.006^{*}$ & $1.004,1.009$ \\
\hline Within-community POR & & $36.97 *$ & & $79.25^{*}$ & & $78.81^{*}$ \\
\hline Within-mother POR & & $92.08 *$ & & $157.71 *$ & & $156.04^{*}$ \\
\hline
\end{tabular}

$* p<0.05$. 
Furthermore, some vaccinators and health care staff have been attacked and even murdered in recent times in Nigeria.

More children received different antigens in 2008 than in previous years, and it is safe to say that more children were immunized in 2003 and 2008 than in previous years (62\% and 60\% respectively). Multi-year analysis of immunization in Nigeria, using survey year as the time factor, suggests a significant association between survey year and the odds of being immunized. The chance of a child being fully vaccinated increased from 19\% in 1999 to about 84\% in 2008 compared with 1990. This indicates an increase in the propensity for full immunization of children over the years, except from 2003 to 2008, which showed a slight trough in the percentage of children that were fully vaccinated (from about $78 \%$ in 2003 to $71 \%$ in 2008). Coverage evaluation was also carried out by the incorporation of a two-way interaction term in the model; there was evidence of progressive coverage of immunization in communities over the years. The interaction term survey year (2008) and community was significant, suggesting an increase in the odds of a child being immunized over time and across communities.

The sex of a child is not associated with the chance of being immunized. The nonsignificance of sex suggests that the odds of a child receiving all doses of the antigens are not affected by the sex of the child. The chance of children from the poorest families being fully immunized decreases by $36 \%$ compared with children of the richest families. Although the proportion of home birth deliveries is very high, most 'completers' are those that had their birth delivery at a public or private health facility. There are more unimmunized children among the home birth delivery group in 1990 and 1999 (Fig. 1). The analysis indicates that children delivered at hospitals have about 1.5 times higher chance of being immunized than children delivered at home. This may be the case in a rural area where the nearest health facility is some kilometres away and where the trekking distance or cost of transportation may deter parents. Also, in some cases the mother may not be strong enough to embark on such trip and some cultural beliefs restrict the mother from going out for the first 40 days after delivery. In such cases, a home visit vaccination service would provide the necessary breakthrough.

Similarly, mother's education plays a significant role in her child's immunization status: a child whose mother is educated has a higher chance (17\%) of completing his/ her immunization than a child from a mother with no education. The proportion of children that are fully immunized is higher when the mother is gainfully employed than when the mother is not gainfully employed. Children of households with a female head are less likely to be immunized than those from male-headed households. An increase in the proportion of households with good sanitation in communities will increase the chance of a child being immunized. These analyses indicate that even after adjusting for known risk factors, some children have a greater propensity to be immunized than others. 
This work is, to the best of the authors' knowledge, the first to provide a multi-year coverage evaluation of vaccination uptake in Nigeria employing DHS data sets using a multi-level technique. Most of the methods used to analyse binary outcome variables are either generalized linear models or their extensions. Rammohan et al. (2012) used logistic regression analysis to explore the likelihood of a child under five years of age being vaccinated for measles separately for Indonesia, India, Pakistan, Nigeria, Democratic Republic of Congo and Ethiopia, while Wiysonge et al. (2012) used multi-level logistic regression to examine the risk factors associated with childhood immunization in 24 countries in sub-Saharan Africa at the child, community and country level. In his study, Antai (2009) employed the use of a three-level multi-level logistic regression model to assess the risk factors for childhood immunization in Nigeria in 2003 using DHS data at the child level nested within mothers who were in turn nested within com- munities. Bosch-Capblanch et al. (2012) carried out a logistic regression analysis on data from 241 nationally representative household surveys in 96 countries using the unique or most recent survey for each country. They dichotomized the vaccination status as children having not received any vaccination ('unvaccinated') vs children who had received at least one dose (partially vaccinated) of any vaccine and fully vaccinated children. The present study's method (Alternating Logistic Regression) allows the simultaneous regressing of the outcome variable on the explanatory variable, as well as modelling of the association among the outcome variables by means of a pairwise odds ratio instead of correlations. The odds ratio provides a better interpretation for binary outcome variables.

Some limitations of this study have been identified. Firstly, the use of survey year as the time factor in cross-sectional data may be seen as a limiting factor; the years of the surveys are not evenly spaced (i.e. 1990, 1999, 2003 and 2008). Secondly, it is difficult to say that the same households or primary sample units were sampled each year, as is the case in longitudinal studies. It would be interesting to be able to identify those households that were sampled over the years. Although the data may have these limitations, they do provide extensive information that is crucial for assessing the risk factors for full immunization over the years.

In conclusion, the significance of the mother- and community-level variability showed the important role played by the mother and community in immunization. This suggests the need for more emphasis on mother- and community-level characteristics. The community-survey year interaction term suggests an increase in the odds of a child being immunized over the years and spread over communities. Evidence-based policy should lay more emphasis on mother- and community-level risk factors in order to ensure that all children are immunized. It is evident in this study that the importance of hospital delivery cannot be overemphasized. Interventions aimed at increasing and encouraging hospital delivery should be put in place to increase the coverage and uptake of vaccination. Parental education is crucial in the uptake of immunization in Nigeria; this could be in the form of community enlightenment and full communication of medical risk to alleviate their fears. Also, it is essential to involve private and independent bodies to provide medical information to the local population 
because of the distrust between the government and the local population, especially in the Northern region. Adequate security should be provided to health care staff and vaccinators to curb the persistent attacks on them in this region.

There is need to reach out to every district and ward through re-establishment of outreach services, community links with service delivery, monitoring and use of data for action planning and management. Routine immunization must be prioritized at every level of government, especially at the local level, in order to capture the local population who are mostly at risk of vaccine-preventable diseases in Nigeria. The national orientation agency has to take drastic action to provide adequate information about immunization to quell rumours about vaccines. Perhaps a vaccination card could be used as a prerequisite for pre-school enrolment in order to identify those children that are not vaccinated. More effort should be made to access hard-to-reach communities, perhaps through home visits. Efforts should be made to make immunization practice more 'patient friendly', for instance by reducing the number of doses required to complete a full course, hence reducing drop-out. The present pentavalent vaccine consisting of diphtheria, pertussis, tetanus, hepatitis $B$ vaccine and Haemophilus influenzae type b vaccines is a welcome innovation, but a single dosage containing all the eight vaccines would be better. 


\section{References}

Abdulraheem, I. S., Onajole, A. T., Jimoh, A. A. G. \& Oladipo, A. R. (2011) Reasons for incomplete vaccination and factors for missed opportunities among rural Nigerian children. Journal of Public Health and Epidemiology 3, 194-203.

Adegboye, O. A. (2010) Under-five mortality in Nigeria: spatial exploration and spatial scan statistics for cluster detection. International Journal of Statistics and Systems 5, 203-214.

Adeiga, A., Omilabu, S., Audu, R., Sanni, F., Lakehinde, G., Balogun, O. \& Olagbaju, O. (2005) Infant immunization coverage in difficult-to-reach area of Lagos Metropolis. African Journal of Clinical and Experimental Microbiology 6, 227231.

Anah, M. U., Etuk, I. S. \& Udo, J. J. (2006) Opportunistic immunization with inpatient programme: eliminating a missed opportunity in Calabar, Nigeria. Annals of African Medicine 5(4), 188-191.

Antai, D. (2009) Inequitable childhood immunization uptake in Nigeria: a multilevel analysis of individual and contextual determinants. BMC Infectious Diseases 9, 181.

Bosch-Capblanch, X., Banerjee, K. \& Burton, A. (2012) Unvaccinated children in years of in- creasing coverage: how many and who are they? Evidence from 96 low- and middle-income countries. Tropical Medicine and International Health 17, 697-710.

Carey, V., Zeger, S. \& Diggle, P. (1993) Modelling multivariate binary data with alternating logistic regressions. Biometrika 80, 517-526.

Diddy, A. (2009) Inequitable childhood immunization uptake in Nigeria: a multilevel analysis of individual and contextual determinants. BMC Infectious Diseases 9, 181.

Diggle, P., Liang, K. Y. \& Zeger, S. (1994) Analysis of Longitudinal Data (second edition). Oxford University Press, Oxford.

Fitzmaurice, G. M., Laird, N. M. \& Ware, J. H. (2004) Applied Longitudinal Analysis. John Wiley and Sons, New York.

Kabir, M., Iliyasu, Z., Abubakar, I. S. \& Nwosuh, J. I. (2004) Immunization coverage among children below two years of age in Fanshakara, Kano, Nigeria. Nigerian Journal of Basic and Clinical Sciences 1(1), 10-13.

Kayode, G. A., Adekanmbi, V. T. \& Uthman, O. A. (2012) Risk factors and a predictive model for under-five mortality in Nigeria: evidence from Nigeria demographic and health survey. BMC Pregnancy and Childbirth 12, 10.

Kunle-Olowu, A., Kunle-Olowu, E. O. \& Ugwu, M. E. (2011) Immunization coverage of antenatal and immunization clinics attendees in the Niger Delta University Teaching Hospital. Journal of Public Health and Epidemiology 3(3), 90-93.

Maekawa, M., Douangmala, S., Sakisaka, K., Takahashi, K., Phathammavong, O., Xeuatvongsa,

A. \& Kuroiwa, C. (2007) Factors affecting routine immunization coverage among children aged 12-59 months in LaoPDR after regional polio eradication in Western Pacific Region. BioScience Trends 1(1), 43-51.

Liang, K. \& Zeger, S. (1986) Longitudinal data analysis using generalized linear models. Bio-metrika 73, 13-22. 
Molenberghs, G. \& Lesaffre, E. (1994) Marginal modelling of correlated ordinal data using a multivariate placket distribution. Journal of the American Statistical Association 89, 633-644.

Molenberghs, G. \& Verbeke, G. (2006) Models for Discrete Longitudinal Data. Springer-Verlag, New York.

National Population Commission (NPC) [Nigeria] \& ICF Macro (2009) Nigeria Demographic and Health Survey 2008. National Population Commission and ICF Macro, Abuja, Nigeria.

Ogunjimi, L. O., Ibe, R. T. \& Ikorok, M. M. (2012) Curbing maternal and child mortality: the Nigerian experience. International Journal of Nursing and Midwifery 4(3), 33-39.

Ogunjuyigbe, P. O. (2004) Under-five mortality in Nigeria: perception and attitudes of the Yorubas towards the existence of 'Abiku'. Demographic Research 11(2), 4356.

Onyiriuka, A. N. (2005) Vaccination default among children attending a static immunization clinic in Benin city, Nigeria. Journal of Medicine and Biomedical Research 4(1), 71-77.

Preisser, J. S., Arcury, T. A. \& Quandt, S. A. (2003) Detecting patterns of occupational illness clustering with alternating logistic regressions applied to longitudinal data. American Journal of Epidemiology 158, 495-501.

SAS Institute Inc. (2008) SAS/STAT 9.2 User's Guide. SAS Institute Inc., Cary, NC.

Sorungbe, A. (1989) Expanded programme on immunization in Nigeria. Reviews of Infectious Diseases 11, S509-511.

Rammohan, A., Awofeso, N. \& Fernandez, R. C. (2012) Paternal education status significantly influences infants' measles vaccination uptake, independent of maternal education status. BMC Public Health 12, 336.

Renne, E. P. (2010) The Politics of Polio in Northern Nigeria. Indiana University Press, Indiana, USA.

UNICEF (2010) At a Glance: Nigeria Statistics. URL: http://www.unicef.org/infobycountry/nigeria statistics.html

United Nations (n.d.) United Nations Millennium Development Goals. URL: http://www.un.org/millenniumgoals/childhealth.html

USAID (n.d.) Immunization Basics: Country Activities. URL: http://www.immunizationbasics. jsi.com/CountryActivities.htm

Wammanda, R., Gambo, M. \& Abdulkadir, I. (2011) Age at BCG administration during routine immunization. Journal of Community Medicine and Primary Health Care 16, 33-35.

WHO (2012a) Fact Sheet on Polio. URL: http://www.who.int/mediacentre/factsheets/fs114/en/ index.html

WHO (2012b) Fact Sheet on Measles. URL: http://www.who.int/mediacentre/factsheets/fs286/en/index.html

WHO (2008) Global Networks for Surveillance of Rotavirus Gastroenteritis, 20012008. Weekly Epidemiological Record, WHO, Switzerland.

Wiysonge, C., Uthman, O., Ndumbe, P. \& Hussey, G. (2012) Individual and contextual factors associated with low childhood immunisation coverage in sub-Saharan Africa: a multilevel analysis. PLoSONE, 7. 